and this behavior does not seem to be influenced by the body composition and muscle performance. The main determinant for this gait pattern remains an open question.

Disclosure of Interests: Fernando Pimentel dos Santos Grant/research support from: From Abbvie and Novartis, Speakers bureau: Abbvie, Novartis, Pfizer, Biogen, Lucia Domingues: None declared, César Mendes: None declared, Ricardo Matias: None declared, Santiago RodriguesManica: None declared, Carolina Crespo: None declared, Jaime Branco: None declared

DOI: 10.1136/annrheumdis-2019-eular.7491

\section{THU0399 DEVELOPMENT OF AN OPTIMIZED ONLINE SELF- REFERRAL TOOL FOR EARLY RECOGNITION OF PATIENTS WITH AXIAL SPONDYLOARTHRITIS (AXSPA) - DATA FROM THE 'OPTIREF'-STUDY}

Fabian Proft ${ }^{1}$, Laura Spiller ${ }^{1}$, Mikhail Protopopov ${ }^{1}$, Valeria Rios Rodriguez ${ }^{1}$, Burkhard Muche ${ }^{1}$, Judith Rademacher ${ }^{1}$, Susanne Lüders ${ }^{1}$, Anne Katrin Weber ${ }^{1}$, Imke Redeker ${ }^{1,2}$, Denis Poddubnyy ${ }^{1,2}$. ${ }^{1}$ Charité Universitätsmedizin, Berlin, Department of Gastroenterology, Infectiology and Rheumatology, 12203 Berlin, Germany; ${ }^{2}$ German Rheumatism Research Centre, Berlin, Germany

Background: One of the major reasons for a long diagnostic delay in axial spondyloarthritis (axSpA) is the late referral of patients by primary care physicians dealing with patients with chronic back pain. We developed and implemented an online self-referral tool (www.bechterew-check de), which gave access to a rheumatological consultation if patients declared suffering from chronic back pain ( $\geq 3$ months) with a symptom onset $\leq 45$ years of age, and at least one feature indicative of SpA. In the prospective "Identification of the Optimal Referral Strategy for Early Diagnosis of Axial Spondyloarthritis (OptiRef) Study" we could diagnose axSpA in $19 \%$ of the self-referred patients [1].

Objectives: To optimize the online-self-referral tool for recognition of patients with high suspicion of axSpA in order to increase the specificity by keeping the high level of sensitivity.

Methods: 181 patients who had fulfilled the online self-referral strategy were included and underwent a standardized rheumatology examination. The final diagnosis of axial $\mathrm{SpA} / \mathrm{no}$ axial $\mathrm{SpA}$ by the rheumatologist served as the gold standard. The performance of all possible combinations of the referral parameters (13 parameters in total including 5 features of inflammatory back pain (IBP) and 8 other SpA features) added to both stem parameters (chronic back pain starting at age of $\leq 45$ years) was tested. In addition, the following pre-specified combinations were evaluated: 1) $\geq 1$ IBP parameter AND $\geq 1$ other SpA parameter, 2) $\geq 1$ IBP parameter $\mathrm{OR}>1$ other SpA parameter. For all combinations, a sensitivity, a specificity, positive and negative predictive values (PPV and NPV), as well as a positive and negative likelihood ratio (LR+ and LR-) were calculated. We targeted the maximal specificity by acceptable sensitivity (defined as $\geq 90 \%$ of the original strategy).

Results: For 163 of the included patients, full data of the online questionnaire as well as of rheumatology examination including the final diagnosis was available. $31(19 \%)$ of them were diagnosed with axial SpA. Raising the threshold of the number of positive parameters (table 1) resulted in a quick drop of the sensitivity. According to the pre-defined selection criterion, only a strategy with any four positive parameters would be acceptable. An analysis of combined strategies (IBP parameters and/ or other SpA parameters) resulted into identification of a strategy with an improved performance: a combination of $\geq 2$ IBP parameters with $\geq 1$ other SpA parameters (in addition to both stem parameters) showed a sensitivity of $90 \%(28 / 31)$, a specificity of $27 \%$ (35/132), a PPV of $22 \%$ $(28 / 125)$, a NPV of $92 \%$ (35/38), LR+ of 1.23 and LR- of 0.36 . Thus, identifying 28 of 31 patients with axSpA would have been possible after the assessment of 125 patients instead of 163 .

Conclusion: The data-driven optimized online self-referral tool (figure 1) requires the following parameters to be positive: chronic back pain ( $\geq 3$ months) plus back pain onset before 45 years of age plus $\geq 2$ IBP parameters plus $\geq 1$ other $\mathrm{SpA}$ feature. The performance of this tool should be confirmed in a prospective study.
Abstract THU0399 -Table 1.

Table 1: Performance of self-referral strategies based on combinations of SpA parameters in addition to the stem parameters (chronic back pain starting at age of $\leq 45$ years).

\begin{tabular}{|c|c|c|c|c|c|c|c|}
\hline $\begin{array}{l}\text { Number of } \\
\text { fuffilied } \\
\text { criteriat (2) }\end{array}$ & $\begin{array}{l}\text { Number of } \\
\text { patients }\end{array}$ & $p p v$ & NPV & Sensitivity & Specificity & LRt & LR - \\
\hline & 163 & $0.19(31 / 163)$ & & $1.00(31 / 31)$ & & & \\
\hline 2 & 158 & $0.20(31 / 158)$ & $1.00(5 / 5)$ & $1.00(31 / 31)$ & $0.04(5 / 132)$ & 1.04 & 0.00 \\
\hline 3 & 147 & $0.21(31 / 147)$ & $1.00(16 / 15)$ & $1.00(31 / 31)$ & $0.12(16 / 132)$ & 1.14 & 0.00 \\
\hline 4 & 128 & $0.22(28 / 128)$ & $0.91(32 / 35)$ & $0.90(28 / 31)$ & $0.24(32 / 132)$ & 1.19 & 0.40 \\
\hline 5 & 114 & $0.23(26 / 114)$ & $0.50(44 / 49)$ & $0.84(26 / 31)$ & $0.33(44 / 132)$ & 1.26 & 0.48 \\
\hline 6 & 74 & $0.31(23 / 74)$ & $0.91(81 / 89)$ & $0.74(23 / 31)$ & \begin{tabular}{|c|c|}
$0 .(81 / 132)$ \\
\end{tabular} & 1.92 & 0.42 \\
\hline 7 & 48 & $0.38(18 / 48)$ & $0.89(102 / 115)$ & $0.58(18 / 31)$ & $0.77(102 / 132)$ & 2.55 & 0.54 \\
\hline 8 & 27 & $0.48(13 / 27)$ & $0.87(118 / 136)$ & $0.42(13 / 31)$ & $0.89(118 / 132)$ & 3.95 & 0.65 \\
\hline 9 & 17 & $0.59(10 / 17)$ & $0.86(125 / 145)$ & $0.32(10 / 31)$ & $0.95(125 / 132)$ & 6.08 & 0.72 \\
\hline 10 & 7 & $0.43(3 / 7)$ & $0.82(128 / 156)$ & $0.10(3 / 31)$ & $0.97(128 / 132)$ & 3.19 & 0.93 \\
\hline 11 & 1 & $1.00(1 / 1)$ & $0.81(132 / 162)$ & $0.03(1 / 31)$ & $1.00(132 / 132)$ & $\cdot$ & 0.97 \\
\hline 12 & 1 & $1.00(1 / 1)$ & $0.81(132 / 162)$ & $0.03(1 / 31)$ & $1.00(132 / 132)$ & $\cdot$ & 0.97 \\
\hline 13 & 1 & $1.00(1 / 1)$ & $0.81(132 / 162)$ & $0.03(1 / 31)$ & $1.00(132 / 132)$ & - & 0.97 \\
\hline
\end{tabular}

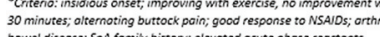

sowel diseose; SpA fomily history; elevoted ocute phose recctonts

Acknowledgements: The OptiRef project was supported by an unrestricted research grant from Novartis.

\section{REFERENCES:}

1. Proft F, et al. EULAR 2018, Abstract THU0230.

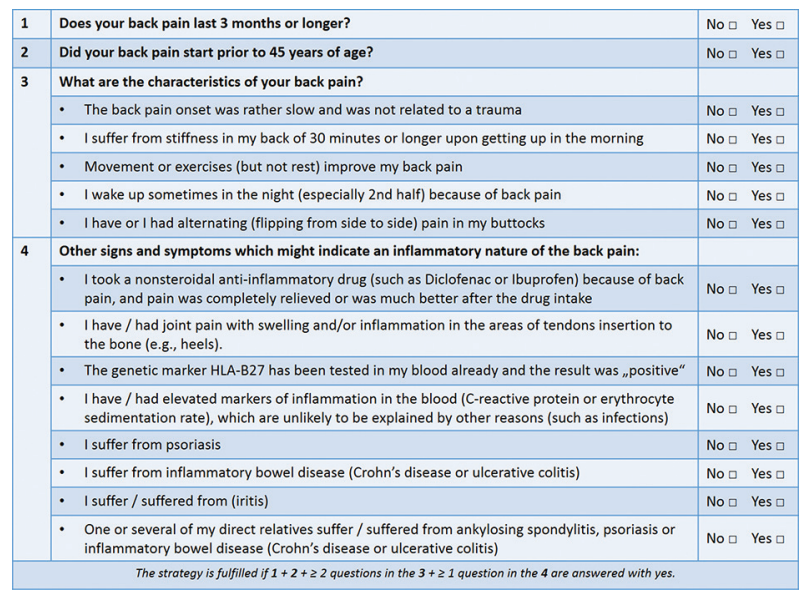

Abstract THU0399 - Figure 1. The data-driven optimized self-referral strategy.

Disclosure of Interests: Fabian Proft Grant/research support from: Novartis, Consultant for: yes but less than 10.000, Paid instructor for: yes but less than 10.000, Speakers bureau: yes but less than 10.000, Laura Spiller: None declared, Mikhail Protopopov: None declared, Valeria Rios Rodriguez: None declared, Burkhard Muche Speakers bureau: Yes less than 10.000, Judith Rademacher: None declared, Susanne Lüders: None declared, Anne Katrin Weber: None declared, Imke Redeker: None declared, Denis Poddubnyy Grant/research support from: AbbVie, Merck Sharp \& Dohme, Novartis, Consultant for: AbbVie, Bristol-Myers Squibb, Janssen, Merck Sharp \& Dohme, Novartis, Pfizer, UCB Pharma, Speak ers bureau: AbbVie, Bristol-Myers Squibb, Janssen, Merck Sharp \& Dohme, Novartis, Pfizer, Roche, UCB Pharma DOI: 10.1136/annrheumdis-2019-eular.4688

\section{THU0400 COMPLICATIONS OF ANTERIOR UVEITIS ASSOCIATED WITH HLA-B27 ANTIGEN IN PATIENTS WITH AND WITHOUT SPONDYLOARTHRITIS}

Irina Razumova ${ }^{1}$, Alla Godzenko ${ }^{2}$, Irina Guseva ${ }^{2} .{ }^{1}$ Research Institute of Eye Disease, Moscow, Russian Federation; ${ }^{2}$ Nasonova Research Institute of Rheumatology, Moscow, Russian Federation

Background: HLA-B27- associated anterior uveitis (AU) can be an isolated disease or part of a systemic inflammatory process, such as spondyloarthritis. Differences in the outcome of uveitis with and without spondyloarthritisare still under researh. 
Objectives: To compare the incidence of complications in HLA-B27- associated anterior uveitis patients with and without spondyloarthritis ( $\mathrm{SpA}$ ). Methods: 189 patients with HLA-B27- associated anterior uveitis were observed in Research Institute of Eye Disease for 10 years. The pts were underwent standard ophthalmological examination, and, if necessary, computer perimetry, ultrasound examination (B-scan.), optical coherence tomography of the retina and optic nerve (OCT), fluorescence fundus angiography (FAGD) and electrophysiological studies (EFI). All pts were examined for clinical and imaging signs of SpA: inflammatory back pain, arthritis, enthesitis, sacroiliitis.

Different variants of SpA were diagnosed in 108 pts: ankylosing spondylitis - in $48(44,4 \%)$, reactive arthritis - in $9(8,3 \%)$, psoriatic arthritis - in $9(8,3 \%)$, inflammatory bowel disease - in $2(1,9 \%)$, juvenile SpA - in 4 $(3,7 \%)$, undifferented SpA - in $36(33,3 \%)$. In 81 pts SpA was not confirmed: 11 had a viral infection (13,5\%), 7- bacterial infection (8,6\%), 1 (1,2\%)-multiple sclerosis, 3 (3,7\%) -psoriasis, 59 (72,8\%)-idiopathic AU.

Results: Complications were identified in 74 of 108 (68,5\%) pts - 147 eyes in SpA-group and in 39of $81(48,1 \%)-110$ eyes in group without SpA. Cataract was identified in $89(60,5 \%)$ of 147 eyes in SpA-group and in $35(1,8 \%)$ of 110 eyes in group without $\mathrm{SpA}, \mathrm{p}=0,0001$; glaucoma in 28 of 147 eyes $(19,0 \%)$ in SpA-group and 8 of 110 eyes $(7,3 \%)$ in group without $\mathrm{SpA}, \mathrm{p}=0,005$; synechia - in $24(16,3 \%)$ and in $8(7,3 \%)$ respectively, $\mathrm{p}=0,021$; vitreous destruction - in $59(40,1 \%)$ and in 26 $(23,6 \%), p=0,005$. Maculopathy, optic atrophy, corneal degeneration, panuveitis were observed more often in SpA-group, but the differences were not significant. Combinations of several complications were detected in 59 $(40,1 \%)$ in SpA-group and in $31(28,2 \%)$ in group without SpA, $p=0,03$. Conclusion: Complications of HLA-B27- associated AU were identified more often in pts with $\mathrm{SpA}$ than without SpA (the majority of which was idiopathic $\mathrm{AU}$ ). It confirms the effect of systemic inflammatory disease on the severity of uveitis.

\section{REFERENCE:}

[1] Yang P, Wan W, Du L, et al. Clinical features of HLA-B27-positive acute anterior uveitis with or without ankylosing spondylitis in a Chinese cohort. Br J Ophthalmol. 2018 Feb;102(2):215-219. doi: 10.1136/bjophthalmol2016-309499. Epub 2017 Jun 12

Disclosure of Interests: None declared

DOI: 10.1136/annrheumdis-2019-eular.2946

\section{THU0401 WOMEN WITH SPONDYLOARTHROPATHIES HAVE HIGHER DISEASE BURDEN ACCORDING TO RAPID3 COMPARED TO MEN, BUT THERE IS NO GENDER DIFFERENCES ACCORDING TO A MODIFIED ASDAS- CRP}

Mariam Riad ${ }^{1}$, Mar Blasco-Blasco², Ofelya Gevorgyan ${ }^{1}$, Isabel Castrejon ${ }^{1} .{ }^{1}$ Rush University Medical Center, Rheumatology, Chicago, United States of America; ${ }^{2}$ University of Alicante, Public Health, Alicante, Spain

Background: Women with Spondyloarthropathies (SpA) may be late or under-diagnoses due to a less typical presentation than in men, with a more peripheral clinical manifestation. Although some studies have suggested a higher burden of disease in women ${ }^{1,2}$, others did not confirm these differences ${ }^{3}, 4$. In addition, women present higher scores for pain and fatigue, which may influence the BASDAI (Bath Ankylosing Spondylitis Disease Activity Index) score ${ }^{5}$.

Objectives: To evaluate possible gender differences in clinical presentation and disease severity in men and women with $\mathrm{SpA}$ in routine care at one academic center.

Methods: All patients complete a Multidimensional Health-Assessment Questionnaire (MDHAQ) as part of their routine care. It includes physical function (FN) (0-10), three 0-10 visual analogue scales (VAS) for pain (PN), patient global estimate (PATGL), and fatigue (FT), RADAI selfreported painful joints, and morning stiffness (MS). Patients with SpA (ICD10 codes) were included: ankylosing spondylitis (AS), psoriatic arthritis (PsA), undifferentiated, and inflammatory bowel disease associated (IBD). Data extracted were clinical presentation, treatment and laboratory tests including C-reactive protein (CRP), HLA-B27 (Human leukocyte antigen), and erythrocyte sedimentation rate (ESR). Composite indices, RAPID3 (030) previously validated in SpA, as the sum of 0-10 scores for FN, PN, and PATGL, and a modified ASDAS-crp using a "back pain" score derived from RADAI neck, back and hips; a "peripheral pain" score derived from the remaining RADAI joints; and MS in minutes were also included. Demographic and clinical characteristics were compared according to gender.
Results: 190 patients were included, $60 \%$ males and $40 \%$ females, with no differences in age, disease duration, and treatment. Men had significantly more frequent inflammatory back pain. Patient global assessment and pain scores were significantly higher in women versus men resulting in a higher RAPID3 (moderate disease severity in both groups). Axial peripheral pain, morning stiffness and laboratory data did not show differences by gender, and as a result ASDAS-CRP was similar between men and women, with a value corresponding to moderate disease activity (Table).

Abstract THU0401 - Table 1. Demographic and clinical characteristics of patients with SpA by gender. Data as median (IQR) unless otherwise specified $\left({ }^{*} \mathrm{p}<0.05\right)$

\begin{tabular}{lcc}
\hline & $\begin{array}{c}\text { Men } \\
\text { N=113 }\end{array}$ & $\begin{array}{c}\text { Women } \\
\mathbf{N}=\mathbf{7 7}\end{array}$ \\
\hline Age (yrs), mean (SD) & $45.2(14.4)$ & $47.0(15.3)$ \\
Self-reported race/ethnicity,\% & $61 / 15 / 13 / 11$ & $50 / 20 / 13 / 17$ \\
White/Black/Hispanic/Others & & \\
Disease duration, (yrs) & $6.1(1.4-11)$ & $5.2(2.1-9.3)$ \\
SpA subgroup,\%: & $57 / 24 / 16 / 3$ & $36 / 29 / 31 / 4^{*}$ \\
AS/PsA/Undifferentiated/IBD & & \\
Peripheral arthritis,\% & $67 \%$ & $69 \%$ \\
Inflammatory back pain\% & $78 \%$ & $63 \%{ }^{*}$ \\
PROs-MDHAQ & & \\
PATGL & $2.5(1.0-5.0)$ & $5.0(2.0-7.0)^{\star}$ \\
Axial pain-RADAI (neck, back and hips) & $4(0.8-5.0)$ & $3.3(1.7-5.8)$ \\
Peripheral pain-RADAl & $0.9(0.2-1.9)$ & $0.9(0-2.6)$ \\
Total PN & $3.0(1.0-6.0)$ & $6.0(2.0-7.5)^{*}$ \\
MS (min) & $30(15-60)$ & $37.5(15-120)$ \\
Fatigue & $2.0(0-6.0)$ & $5(2.0-8.0)^{*}$ \\
Laboratory Data & & \\
HLA-B27 positive,\% & $66.7 \%$ & $67.4 \%$ \\
CRP (mg/L) & $5(5-15.6)$ & $5(5-15.6)$ \\
ESR (mm/h) & $12(4-29)$ & $19.5(9-33)$ \\
Composite index, mean (SD) & & \\
RAPID3 & $7.7(6.9)$ & $10.9(7.5)^{*}$ \\
Modified ASDAS-CRP & $1.8(0.9)$ & $1.9(0.9)$ \\
\hline
\end{tabular}

Conclusion: Women with SpA have higher RAPID3 scores than men, in contrast to a modified ASDAS-CRP based on scores from the MDHAQ which did not show gender differences. These data suggest that RAPID3 scores in women may be attributable in part to a gender bias rather than clinical severity and a careful interpretation in the context of gende is necessary.

\section{REFERENCES :}

[1] Ann Rheum Dis. 2013; 72(7):1221-4

[2] Reumatol Clin. 2013; 9(4):221-5.

[3] Rheumatology (Oxford). 2014; 53(5):875-81.

[4] Clin. Rheumatol. 2015; 34(2):285-93.2015.

[5] Ann Rheum Dis. 2017; 76: Suppl.2. 657-658.

Disclosure of Interests: None declared DOI: 10.1136/annrheumdis-2019-eular.4343

\section{THU0402 CONTRIBUTION OF THE EOS IMAGING SYSTEM IN ASSESSING PELVIC AND SPINAL DEFORMITIES IN SPONDYLOARTHRITIS}

Meriem Sellami ${ }^{1}$, Wafa Hamdi ${ }^{1}$, Hend Riahi ${ }^{2}$, Kaouther Maatallah ${ }^{1}$,

Hanen Ferjani ${ }^{1}$, Dhia Kaffel ${ }^{1}$, Mohamed Montacer Kchir ${ }^{1} .{ }^{1}$ Kassab Institute, Rheumatology, Mannouba, Tunisia; ${ }^{2}$ Kassab Institute, Radiology, Mannouba, Tunisia

Background: The severity of Spondyloarthritis (SA) lies mainly in the progressive ankylosis of the axial skeleton and the deformations generated. The means of assessing the spinal static disorders in SA are currently subjective and difficult to reproduce. Multidisciplinary collaboration has led to the development of a new biplane low dose radiology technology named EOS. It allows a simultaneous acquisition of the axial skeleton and the lower limbs in a standard standing position.

Objectives: We aimed to assess pelvic and spinal parameters and spinal stature in patients with SA using the EOS system.

Methods: This is a prospective cross-sectional study conducted over a 10-month period (January-October 2018) involving 50 patients with SA meeting the criteria of Assessment of SpondyloArthritis International Society. An entire body EOS examination of the vertebral column in a stand ardized standing position was performed in all patients. Pelvic parameters measured by the EOS system were pelvic incidence ( $\mathrm{PI}$ : normal value 